\title{
Performance Enhancement of $\mathrm{CuO} / \mathrm{ZnO}$ by Deposition on the Metal-Organic Framework of Cu-BTC for Methanol Steam Reforming Reaction
}

\author{
Hangyu Yu, ${ }^{1}$ Chao Xu, ${ }^{1, *}$ Yuanzhi Li, ${ }^{1}$ Fei Jin, ${ }^{1}$ Feng $\mathrm{Ye}^{1}$ and $\mathrm{Xin} \mathrm{Li}^{2}$
}

\begin{abstract}
A b stract
The commonly used $\mathrm{CuO} / \mathrm{ZnO}$ catalysts are prone to show unsatisfying performance at higher temperatures for hydrogen generation through methanol steam reforming (MSR) reaction, and thus catalyst modifications are required to enhance the performance of catalysts. In this study, CuO/ZnO was successfully loaded on a metal-organic framework material (Cu-BTC) by the impregnation method, with different masses of Cu-BTC. The catalyst ingredients and microstructure were characterized, and the catalytic performance at the temperature range from 200 to $340{ }^{\circ} \mathrm{C}$ was investigated in an MSR test system. The catalytic activity, anti-deactivation ability and stability performance of CuO/ZnO/Cu-BTCs were found to be much better than that of $\mathrm{CuO} / \mathrm{ZnO}$. The hydrogen concentration and hydrogen generation rate of CuO/ZnO/Cu-BTCs with 0.5 and $1 \mathrm{~g}$ Cu-BTC were increased by about $100 \%$ and $1000 \%$, respectively, comparing with the $\mathrm{CuO} / \mathrm{ZnO}$ catalyst at $300{ }^{\circ} \mathrm{C}$. Although superfluous CU-BTC caused the evident reduction of catalytic activity at low temperatures, no obvious deactivation happened at higher temperatures. The deposition of $\mathrm{CuO} / \mathrm{ZnO}$ on $\mathrm{Cu}-\mathrm{BTC}$ has great potential to enhance the performance at higher temperatures for hydrogen generation through MSR reaction.
\end{abstract}

Keywords: $\mathrm{CuO} / \mathrm{ZnO} / \mathrm{Cu}-\mathrm{BTC}$; methanol steam reforming; metal-organic framework; thermochemical energy storage; hydrogen

Received: 29 January 2020; Accepted: 5 May 2020

Article type: Research article

\section{Introduction}

During the last decades, global warming and other environmental issues have forced more and more countries to apply stringent regulations about fossil fuel utilization and pay more attention to energy storage technologies. ${ }^{[1]}$ Thermochemical energy storage technology is a promising way for energy storage with high energy density and long storage time..$^{[2-4]}$ Among various thermochemical energy storage technologies, the methanol steam reforming (MSR)

\footnotetext{
Key Laboratory of Condition Monitoring and Control for Power Plant Equipment of MOE, North China Electric Power University, Beijing 102206, China

${ }^{2}$ Key Laboratory of Solar Thermal Energy and Photovoltaic System, Institute of Electrical Engineering, Chinese Academy of Sciences, Beijing, 100190, China

*E-mail: mechxu@ncepu.edu.cn (C.Xu)
}

reaction is a striking method for its ability to generate massive hydrogen, which also surmounts the transit difficulty and storage problem of hydrogen. ${ }^{[5-7]}$ What's more, the reacting temperature of MSR typically ranges from 180 to $400{ }^{\circ} \mathrm{C}$, which is much lower than the reacting temperature of methane dry reforming, methane steam reforming and ethanol steam reforming. ${ }^{[6,8-10]}$ The whole MSR reaction can be described by the following chemical reactions:

$$
\begin{array}{cc}
\mathrm{CH}_{3} \mathrm{OH}+\mathrm{H}_{2} \mathrm{O}=\mathrm{CO}_{2}+3 \mathrm{H}_{2} & \Delta \mathrm{H}=+49.7(\mathrm{~kJ} / \mathrm{mol}) \\
\mathrm{CH}_{3} \mathrm{OH}=\mathrm{CO}+2 \mathrm{H}_{2} & \Delta \mathrm{H}=+90.7(\mathrm{~kJ} / \mathrm{mol}) \\
\mathrm{CO}+\mathrm{H}_{2} \mathrm{O}=\mathrm{CO}_{2}+\mathrm{H}_{2} & \Delta \mathrm{H}=-41.2(\mathrm{~kJ} / \mathrm{mol})
\end{array}
$$

Experimental parameters like the structure of reformer ${ }^{[11-13]}$ and catalyst modification have an impact on the performance of MSR reaction. ${ }^{[14-17]}$ Recently, the investigation about the 
MSR reaction focuses on the copper-based catalyst for its low cost. ${ }^{[18,19]}$ Among all the copper-based catalysts, $\mathrm{CuO} / \mathrm{ZnO}$ is the most common one, due to its wide utilization in methanol steam reforming field. However, $\mathrm{CuO} / \mathrm{ZnO}$ shows good catalytic activity only at temperature of around $250{ }^{\circ} \mathrm{C}$, and deactivation typically happens at temperatures larger than $250{ }^{\circ} \mathrm{C}^{[5]}$ To improve the catalytic activity, anti-deactivation ability and stability performance of $\mathrm{CuO} / \mathrm{ZnO}$ at higher temperatures, $\mathrm{CuO} / \mathrm{ZnO}$ catalysts were modified in different ways. Mateos-Pedrero et al. ${ }^{[2]}$ changed the surface area and polarity ratio of $\mathrm{ZnO}$ in $\mathrm{CuO} / \mathrm{ZnO}$ catalyst and found that higher polarity ratio contributed to better catalytic performance, but no deactivation analysis of the catalysts was carried out in their study. $\mathrm{Pu}$ et $a l^{[21]}$ modified $\mathrm{CuO} / \mathrm{ZnO}$ catalysts with the addition of Sc, by which the hydrogen production rate of $\mathrm{CuO} / \mathrm{ZnO} / \mathrm{Sc}_{2} \mathrm{O}_{3}$ at temperatures higher than $260{ }^{\circ} \mathrm{C}$ was increased by three times. Besides, $\mathrm{Al}_{2} \mathrm{O}_{3}$ was utilized as a promoter of the $\mathrm{CuO} / \mathrm{ZnO}$ catalysts as well. However, most of the activity tests were carried out at temperatures from 200 to $260{ }^{\circ} \mathrm{C}$, and no deactivation analysis of the $\mathrm{CuO} / \mathrm{ZnO} / \mathrm{Al}_{2} \mathrm{O}_{3}$ was performed as well. ${ }^{[1,22-25]}$ Likewise, Pan et al. ${ }^{[26]}$ and $\mathrm{Zhou}$ et al. ${ }^{[2]}$ added $\mathrm{Zr}$ to improve the reducibility of copper and achieve higher metal surface area, but the deactivation phenomenon was also ignored. In summary, the modification materials of the $\mathrm{CuO} / \mathrm{ZnO}$ catalysts in the previous works mainly included aluminum, zirconium and strontium, whose influence on the catalytic activity and anti-deactivation ability at temperatures higher than $260{ }^{\circ} \mathrm{C}$ was either unsatisfying or seldomly analyzed. Besides, the supports mentioned above had impacts on the catalyst structure, while, they would not assist copper with the MSR reaction. Thus, it would be better if there is one material with the splendid supporting capability and ability to assist copper with the MSR reaction. Cu-BTC (metal-organic framework material) could serve as the dual-functional supporting material for the MSR reaction due to its unique structure and ability to participate in the MSR reaction.

Cu-BTC (MOF-199, HKUST-1), proposed by Chui et $a l .{ }^{[28]}$ is one kind of metal-organic framework (MOF) materials, most of which have been utilized in various fields. ${ }^{[2-34]} \mathrm{Cu}$-BTC utilizes copper ion as the connection point with TMA (benzene-1,3,5-tricarboxylate) as ligands. Concerning the structure of $\mathrm{Cu}-\mathrm{BTC}$, the polymer with facecentered-cubic crystals contains an intersecting threedimensional (3D) system of large square-shaped pores ( $9 \AA$ by $9 \AA$ ). Moreover, according to the thermogravimetric analysis characterization, ten $\mathrm{H}_{2} \mathrm{O}$ molecules don 't function as the structure connection in each $\mathrm{Cu}-\mathrm{BTC}$ unit, which indicates that there are unsaturation coordination points in $\mathrm{Cu}-\mathrm{BTC}$. The unique $3 \mathrm{D}$ porous structure and unsaturation coordination points endow $\mathrm{Cu}-\mathrm{BTC}$ with splendid supporting ability, which have been utilized in many fields. Ökte et al. ${ }^{[35]}$ loaded $\mathrm{ZnO}$ along with $\mathrm{TiO}_{2}$ on the $\mathrm{Cu}-\mathrm{BTC}$ and tested the adsorption and photocatalytic performance of the composites. $\mathrm{Cu}$-BTC based composites showed higher dark adsorption abilities and higher degradation efficiencies toward methylene blue. Wee et al ${ }^{[36]}$ loaded Keggin phosphotungstic acid on $\mathrm{Cu}-$ BTC and applied the composites to the esterification reaction of acetic acid and propanol. When the ratio of acetic acid and propanol was $1: 40$, the best catalytic performance was achieved at the catalyst size of $50 \mathrm{~nm}$. Zhao et al ${ }^{[3]}$ loaded silver on $\mathrm{Cu}$-BTC and treated the composites at $250{ }^{\circ} \mathrm{C}$ to obtain $\mathrm{Ag} / \mathrm{Cu}_{\mathrm{x}} \mathrm{O}(\mathrm{x}=1.2)$ nanoparticles. The synergy between $\mathrm{Cu}_{\mathrm{x}} \mathrm{O}$ and $\mathrm{Ag}$ enhanced the catalytic activity for $\mathrm{CO}$ oxidation. However, based on the researches mentioned above, it is found that $\mathrm{Cu}-\mathrm{BTC}$ has not been used in the MSR reaction yet.

Due to that $\mathrm{Cu}-\mathrm{BTC}$ has a unique structure and copper core, it is of great potential to support the $\mathrm{CuO} / \mathrm{ZnO}$ catalyst and improve the catalytic activity and anti-deactivation ability at higher temperatures. In this study, $\mathrm{CuO} / \mathrm{ZnO}$ was loaded on $\mathrm{Cu}-\mathrm{BTC}$ by the impregnation method. For comparison, a regular $\mathrm{CuO} / \mathrm{ZnO}(\mathrm{CZ})$ catalyst was also prepared. The catalysts were characterized through various ways to investigate the microstructure and the elemental distribution. Besides, an MSR system with a conventional quartz tubular reactor was built for the catalytic activity tests at the broad temperature range from 200 to $380{ }^{\circ} \mathrm{C}$. By combining the characterization of the catalysts with the catalytic performance and the anti-deactivation ability, the overall performance of the $\mathrm{CuO} / \mathrm{ZnO} / \mathrm{Cu}-\mathrm{BTC}$ and the effect of the $\mathrm{Cu}-\mathrm{BTC}$ as supports were analyzed.

\section{Experimental}

\subsection{Preparation of $\mathrm{Cu}$-BTC supports}

Cu-BTC (HKUST-1, MOF-199) samples were prepared by the hydrothermal method. ${ }^{[28]} 4.5 \mathrm{mmol}(1.1075 \mathrm{~g})$ copper nitrate trihydrate (AR 99\% purity, Aladdin Reagent (Shanghai) Co., Ltd.) was dissolved in $15 \mathrm{~mL}$ ultra-pure water, while $2.5 \mathrm{mmol}$ $(0.6363 \mathrm{~g})$ benzene-1,3,5-tricarboxylate (98\% purity, Aladdin Reagent (Shanghai) Co., Ltd.) was dissolved in $15 \mathrm{~mL}$ ethanol ( $\geq 99.5 \%$ purity, Aladdin Reagent (Shanghai) Co., Ltd.). The two solutions were placed separately in the ultrasonic machine, which run in $50 \mathrm{~Hz}$ for 15 min to obtain the fully dissolved solutions, and then they were mixed in a $50 \mathrm{~mL}$ para polyphenyl lined stainless autoclave that was kept at $120{ }^{\circ} \mathrm{C}$ for $24 \mathrm{~h}$. The autoclave was cooled down to the ambient temperature naturally. Then, the resultant was filtered and washed with ethanol and ultra-pure water by vacuum filtration to get rid of the trace $\mathrm{Cu}_{2} \mathrm{O}$. Eventually, the obtained cyan $\mathrm{Cu}-$ BTC was dried at $120^{\circ} \mathrm{C}$ for $12 \mathrm{~h}$.

\subsection{Preparation of $\mathrm{CuO} / \mathrm{ZnO} / \mathrm{Cu}$-BTCs}

The main preparation procedure of $\mathrm{CuO} / \mathrm{ZnO} / \mathrm{Cu}-\mathrm{BTC}$ is illustrated in Fig. 1. $\mathrm{CuO} / \mathrm{ZnO} / \mathrm{Cu}-\mathrm{BTC}$ catalysts were prepared by the impregnation method. $36.8 \mathrm{mmol}(8.8876 \mathrm{~g})$ 


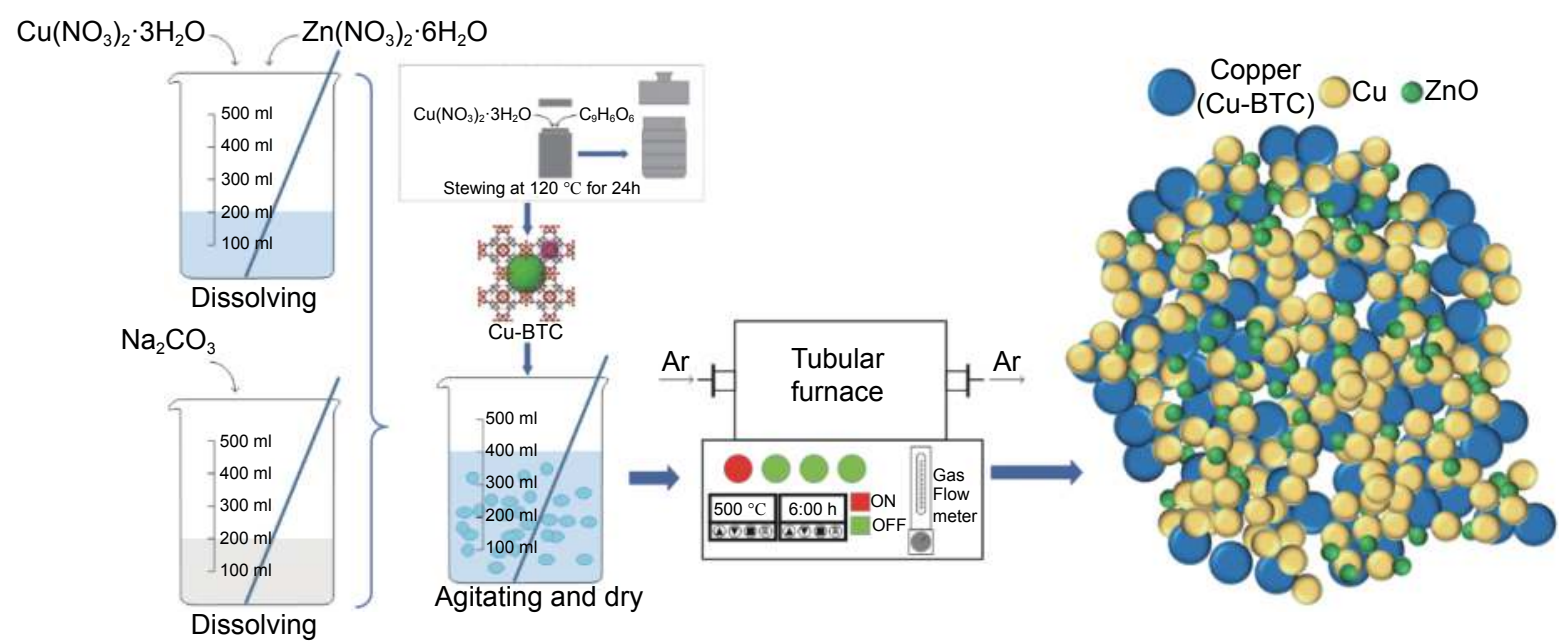

Fig. 1 Main fabrication procedure of $\mathrm{CuO} / \mathrm{ZnO} / \mathrm{Cu}-\mathrm{BTCs}$.

copper nitrate trihydrate (AR 99\%, Aladdin Reagent (Shanghai) Co., Ltd.) and $13.2 \mathrm{mmol}$ (3.9309 g) zinc nitrate hexahydrate (AR 99\%, Aladdin Reagent (Shanghai) Co., Ltd.) were completely dissolved in $200 \mathrm{~mL}$ ultra-pure water, and $51.2 \mathrm{mmol}(5.4396 \mathrm{~g})$ sodium carbonate ( $\mathrm{AR} \geq 99.5 \%$, Shanghai Macklin Biochemical Co., Ltd.) was dissolved in $200 \mathrm{~mL}$ ultra-pure water. The nitrate solution was slowly added into the sodium carbonate solution with vigorous stirring, and the resulting $\mathrm{CuCO}_{3} / \mathrm{ZnCO}_{3}$ suspensions were continuously agitated for $2 \mathrm{~h}$ at the ambient temperature to guarantee total coprecipitation. After $2 \mathrm{hrs}$ continuous agitation, $\mathrm{Cu}-\mathrm{BTC}$ powders were slowly added into the agitating $\mathrm{CuCO}_{3} / \mathrm{ZnCO}_{3}$ suspensions. Different masses $(0.5 \mathrm{~g}$, $1 \mathrm{~g}, 2 \mathrm{~g}, 4 \mathrm{~g}$ ) of $\mathrm{Cu}-\mathrm{BTC}$ powders were added in the experiments to investigate the effect of $\mathrm{Cu}-\mathrm{BTC}$ content on the catalyst performance. The resulting mixtures were continuously stirred for $12 \mathrm{hrs}$ at the room temperature and washed several times with ultra-pure water. Drying was performed at $120{ }^{\circ} \mathrm{C}$ for $12 \mathrm{hrs}$ followed by the calcination at $500{ }^{\circ} \mathrm{C}$ for $6 \mathrm{hrs}$ with the protection of argon. Calcined $\mathrm{CuO} / \mathrm{ZnO} / \mathrm{Cu}-\mathrm{BTC}$ catalysts were tableted under $5 \mathrm{MPa}$ pressure and then crushed. Particles ( $1 \mathrm{~g}$ ) of size 40-60 mesh were sieved and mixed with $1 \mathrm{~g}$ quartz sand of size 50-80 mesh (Shanghai Macklin Biochemical Co., Ltd.) for the subsequent catalytic performance tests. The obtained composites were named as CZC-0.5, CZC-1, CZC-2, CZC-4, respectively, corresponding to the different $\mathrm{Cu}$-BTC addition masses of $0.5 \mathrm{~g}, 1 \mathrm{~g}, 2 \mathrm{~g}$, and $4 \mathrm{~g}$.

$\mathrm{CuO} / \mathrm{ZnO}$ was also prepared by the coprecipitation method, comparing the performance of the prepared $\mathrm{CuO} / \mathrm{ZnO} / \mathrm{Cu}-\mathrm{BTC}$ with the conventional $\mathrm{CuO} / \mathrm{ZnO}$. The production of $\mathrm{CuCO}_{3} / \mathrm{ZnCO}_{3}$ suspension used the same procedure as mentioned in the preparation of $\mathrm{CuO} / \mathrm{ZnO} / \mathrm{Cu}$ BTCs. The obtained $\mathrm{CuCO}_{3} / \mathrm{ZnCO}_{3}$ suspensions were filtered and washed several times with ultra-pure water to remove the unreacted nitrates and sodium carbonate. The purified resultant was dried in air at $120^{\circ} \mathrm{C}$ for $12 \mathrm{hrs}$. The obtained dry material was ground into powders and calcined at $500{ }^{\circ} \mathrm{C}$ for $6 \mathrm{hrs}$, during which argon was utilized for protection. The $\mathrm{CuO} / \mathrm{ZnO}$ catalyst was tableted under $5 \mathrm{MPa}$ pressure and then crushed. $1 \mathrm{~g}$ particles of size 40-60 mesh were sieved and mixed with $1 \mathrm{~g}$ quartz sand of size 50-80 mesh (Shanghai Macklin Biochemical Co., Ltd.) for the subsequent catalytic performance tests. Besides, the obtained composite was denoted as CZ.

\subsection{Characterization of $\mathrm{CuO} / \mathrm{ZnO} / \mathrm{Cu}-\mathrm{BTCs}$}

The X-ray diffraction (XRD) patterns of $\mathrm{Cu}$-BTC were obtained on the Bruker D8 Focus X-ray Diffractometer at $40 \mathrm{kV}$ and $40 \mathrm{~mA}$ from $5^{\circ}$ to $40^{\circ}$ and with a scan speed of 0.05 second/step, while the XRD patterns of $\mathrm{CuO} / \mathrm{ZnO} / \mathrm{Cu}-\mathrm{BTCs}$ and $\mathrm{CuO} / \mathrm{ZnO}$ were obtained at $40 \mathrm{kV}$ and $40 \mathrm{~mA}$ from $5^{\circ}$ to $80^{\circ}$ with a scan speed of 0.05 second/step. The scanning electron microscope (SEM) images of the catalysts were recorded by the JSM-7800F Schottky Field Emission Scanning Electron Microscope. Before scanning, gold sputtering treatment was applied to the materials for better electric conduction.

To investigate the microstructure and morphology of the catalysts, $\mathrm{CuO} / \mathrm{ZnO} / \mathrm{Cu}-\mathrm{BTCs}$ and $\mathrm{CuO} / \mathrm{ZnO}$ were subjected to a Tecnai G2 F30 field Emission Gun Transmission Electron Microscope at $300 \mathrm{kV}$. The samples were dispersed in ethanol by ultrasonication and a drop of the solution was deposited onto a thin copper film. Meanwhile, the elemental analysis was performed on an energy dispersive X-ray analysis unit fixed in the TEM equipment.

\subsection{Catalytic activity tests of $\mathrm{CuO} / \mathrm{ZnO} / \mathrm{Cu}-\mathrm{BTCs}$}

A methanol steam reforming reaction system was constructed for the catalytic activity tests. The flow chart is shown in Fig. 2. Four components made up the whole system including a reactant injection part, a heating part, a condensation part and a syngas analysis part. In the reactant injection part, a peristaltic pump was utilized to inject methanol solution. To 


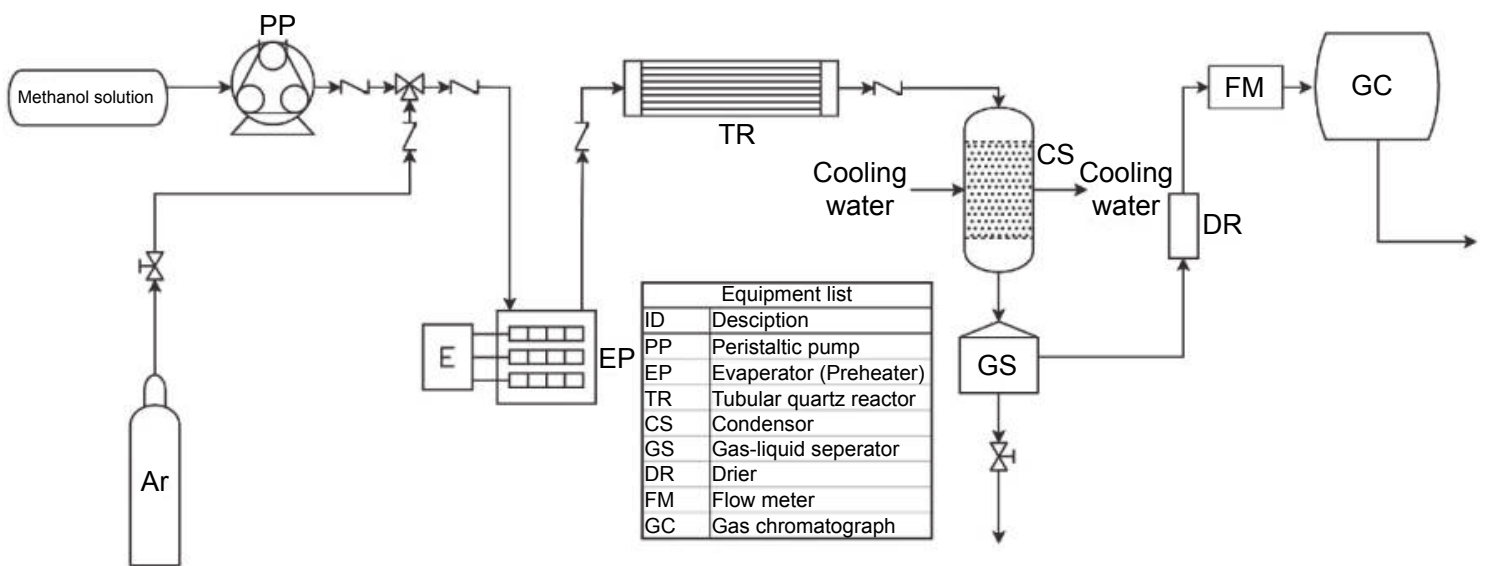

Fig. 2 The flow chart of the MSR reaction performance evaluation system.

maintain steady syngas flow, the flow rate of the carrier gas and argon was controlled by a flow meter. As for the heating part, an evaporator with sprayer ensured the complete evaporation of methanol and water. Furthermore, the evaporator also functioned as a preheater to assist the tubular quartz reactor, which was loaded with $2 \mathrm{~g}$ composites $(1 \mathrm{~g}$ catalysts mixed with $1 \mathrm{~g}$ quartz sand). In the condensation part, a condenser was placed before the gas-liquid separator to cool the high-temperature syngas down. The unreacted methanol and water were deposited in the separator in the liquid phase. In the syngas analysis part, the syngas from the separator was dried by a drier, while the flow rate was measured by a flow meter and the syngas was eventually analyzed by a gas chromatograph (Shimadzu GC-2014).

The operating processes of the tests are introduced below. First, the argon flow rate was kept at around $15 \mathrm{~mL} / \mathrm{min}$ for half an hour to get rid of the air in the whole system. Second, when the tubular quartz reactor loaded with $2 \mathrm{~g}$ catalyst mixture was heated up to the setting temperature with the rate of $10{ }^{\circ} \mathrm{C} / \mathrm{min}$, the evaporator started to be heated to $200{ }^{\circ} \mathrm{C}$. Third, the peristaltic pump which was set at around $0.7 \mathrm{~mL} / \mathrm{min}$ started to inject the methanol solution, where the
$\mathrm{H}_{2} \mathrm{O} / \mathrm{CH}_{3} \mathrm{OH}(\mathrm{S} / \mathrm{C})$ molar ratio was $1.1 / 1$ and the ratio of weight of catalyst to feed of methanol solution (W/F) was $1.4(\mathrm{~g} \cdot \mathrm{min} / \mathrm{mL})$. At last, the gas chromatograph was started to analyze the ingredients of the syngas.

Several parameters were detected and calculated to evaluate the MSR reaction performance of $\mathrm{CuO} / \mathrm{ZnO} / \mathrm{Cu}-\mathrm{BTC}$, including the hydrogen concentration $\left(\mathrm{N}_{\mathrm{H}_{2}}\right)$, the hydrogen selectivity $\left(\mathrm{S}_{\mathrm{H}_{2}}\right)$, the $\mathrm{CO}$ concentration $\left(\mathrm{N}_{\mathrm{CO}}\right)$, the $\mathrm{CO}$ selectivity $\left(\mathrm{S}_{\mathrm{CO}}\right)$ and the hydrogen generation rate $\left(\mathrm{V}_{\mathrm{H}_{2}}\right)$. The hydrogen concentration and $\mathrm{CO}$ concentration were detected by the gas chromatograph, and other parameters mentioned above were calculated by the following equations:

$$
\begin{gathered}
\text { Hydrogen selectivity: } \mathrm{S}_{\mathrm{H}_{2}}=\frac{\mathrm{N}_{\mathrm{H}_{2}}}{\mathrm{~N}_{\mathrm{H}_{2}}+\mathrm{N}_{\mathrm{CO}}} \\
\text { CO selectivity: } \mathrm{S}_{\mathrm{CO}}=\frac{\mathrm{N}_{\mathrm{CO}}}{\mathrm{N}_{\mathrm{H}_{2}}+\mathrm{N}_{\mathrm{CO}}}
\end{gathered}
$$

Hydrogen generationrate: $\mathrm{V}_{\mathrm{H}_{2}}=\mathrm{V}_{\text {syngas }} \times \mathrm{N}_{\mathrm{H}_{2}} \times \mathrm{e}$

where $\mathrm{V}_{\text {syngas }}$ is the syngas flow rate detected by the flow meter before the gas chromatograph and $\mathrm{e}$ is the modification coefficient of the syngas flow rate given by the manufacturer HORIBA.

$$
\mathrm{e}=\frac{0.3106 \times\left(\mathrm{N}_{\mathrm{H}_{2}}+1 \times \mathrm{N}_{\mathrm{CO}}+1.01 \times\left(1-\mathrm{N}_{\mathrm{H}_{2}}-\mathrm{N}_{\mathrm{CO}}\right)\right)}{\rho_{\mathrm{H}_{2}} \times \mathrm{C}_{\mathrm{p}_{\mathrm{H}_{2}}} \times \mathrm{N}_{\mathrm{H}_{2}}+\rho_{\mathrm{CO}} \times \mathrm{C}_{\mathrm{p}_{\mathrm{CO}}} \times \mathrm{N}_{\mathrm{CO}}+\rho_{\mathrm{Ar}} \times \mathrm{C}_{\mathrm{p}_{\mathrm{Ar}}} \times\left(1-\mathrm{N}_{\mathrm{H}_{2}}-\mathrm{N}_{\mathrm{CO}}\right)} \div 1.415
$$

where $\rho_{\mathrm{H}_{2}}, \rho_{\mathrm{CO}}$ and $\rho_{\mathrm{Ar}}$ represent the density of hydrogen, carbon monoxide and argon, while $\mathrm{C}_{\mathrm{p}_{2}}, \mathrm{C}_{\mathrm{p}_{\mathrm{CO}}}$ and $\mathrm{C}_{\mathrm{p}_{\mathrm{Ar}}}$ are the corresponding constant-pressure specific heats.

\section{Results and discussion}

\subsection{Properties and characterization of $\mathrm{CuO} / \mathrm{ZnO} / \mathrm{Cu}-\mathrm{BTCs}$, $\mathrm{CuO} / \mathrm{ZnO}$ and $\mathrm{Cu}-\mathrm{BTC}$}

The XRD patterns of CZ, CZC-0.5, CZC-1, CZC-2, CZC-4 are shown in Fig. 3. The catalysts showed diffractions of $\mathrm{d} 100, \mathrm{~d}$ 002, d 101, d 102, d 110 and d 103 at $31.7^{\circ}, 34.4^{\circ}, 36.2^{\circ}$, $47.5^{\circ}, 56.5^{\circ}$ and $62.8^{\circ}$, respectively, which demonstrates the existence of zinc oxide, while diffraction peaks of $\mathrm{d} 110, \mathrm{~d}$ 111, $\mathrm{d} 020$ and $\mathrm{d} 211$ at $32.5^{\circ}, 38.7^{\circ}, 53.4^{\circ}$ and $66.1^{\circ}$ demonstrate the successful synthesis of copper oxide. However, copper peaks of d 111, d 200 and d 220 at $43.3^{\circ}$, $50.4^{\circ}$ and $74.1^{\circ}$, respectively, appeared in the patterns of $\mathrm{CZC}$ 1, CZC-2, CZC-4, indicating the added Cu-BTC might be superfluous. In this case, it is proved that the superfluous $\mathrm{Cu}$ BTC will be calcined into copper at $500{ }^{\circ} \mathrm{C}$, which could assist the copper from the coprecipitation with the catalytic activity.

In the desiccation process of the $\mathrm{Cu}$-BTC fabrication, the existence of air had a significant impact on the color of $\mathrm{Cu}$ BTC. When the Cu-BTC was dried in the air, the resulting material demonstrated aquamarine. However, the $\mathrm{Cu}$-BTC was dark blue when dried in vacuum circumstance. The $\mathrm{Cu}-\mathrm{BTC}$ dried in vacuum turned to aquamarine as well when exposed in the air for a long time. In case that the structure of $\mathrm{Cu}$-BTC 
was affected during the desiccation, the XRD patterns of the $\mathrm{Cu}$-BTC under different dry conditions were obtained and are shown in Fig. 4. The calculated XRD curve was derived from Chui et al. ${ }^{[28]}$ Whatever the dry condition was, the fabricated $\mathrm{Cu}$-BTC's XRD patterns correspond to the patterns in the literature well at $5.8^{\circ}, 6.7^{\circ}, 9.5^{\circ}, 11.6^{\circ}, 13.4^{\circ}, 14.7^{\circ}, 16.5^{\circ}$ and $19^{\circ}$. Therefore, the property of $\mathrm{Cu}-\mathrm{BTC}$ has nothing to do with the dry condition. What's more, it is known that the $\mathrm{Cu}$-BTC trihydrate is aquamarine and will be dehydrated at $120{ }^{\circ} \mathrm{C}$ into anhydrous $\mathrm{Cu}-\mathrm{BTC}$ which is dark blue and cannot decompose until $240{ }^{\circ} \mathrm{C}$. The anhydrous Cu-BTC exposed in the air will adsorb water and turn into $\mathrm{Cu}-\mathrm{BTC}$ trihydrate sooner or later. In summary, the resulting material dried in the air was $\mathrm{Cu}-\mathrm{BTC}$ trihydrate due to the presence of water in the air, while the resulting material dried in vacuum was anhydrous $\mathrm{Cu}$-BTC.

The SEM images of Cu-BTC are shown in Fig. 5. In the micrometer scale, the fabricated $\mathrm{Cu}-\mathrm{BTC}$ shows a faceted octahedral structure, which is consistent with Ref. [28] and suggests that the $\mathrm{Cu}-\mathrm{BTC}$ is of splendid support capability.

The SEM images of CZ, CZC-0.5, CZC-1, CZC-2, CZC4 are presented in Fig. 6. Each catalyst was scanned at both $3,000 \mathrm{x}$ and 10,000x magnifications to observe the overall structure and small particles on the surface. It is clear that nanoparticles were observed on the surface of the catalysts, and small distinctions existed for different addition masses of Cu-BTC. Besides, CZ showed the smallest particle size among the catalysts, while the particle size of CZC-0.5 was slightly

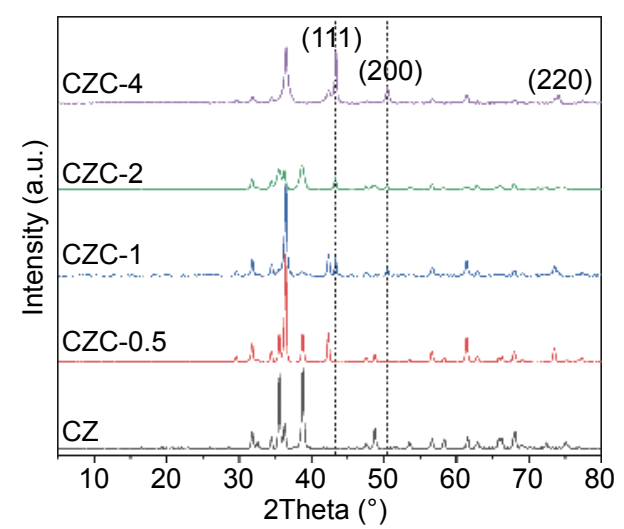

Fig. 3 The X-ray diffractograms of CZ, CZC-0.5, CZC-1, CZC-2 and CZC-4.

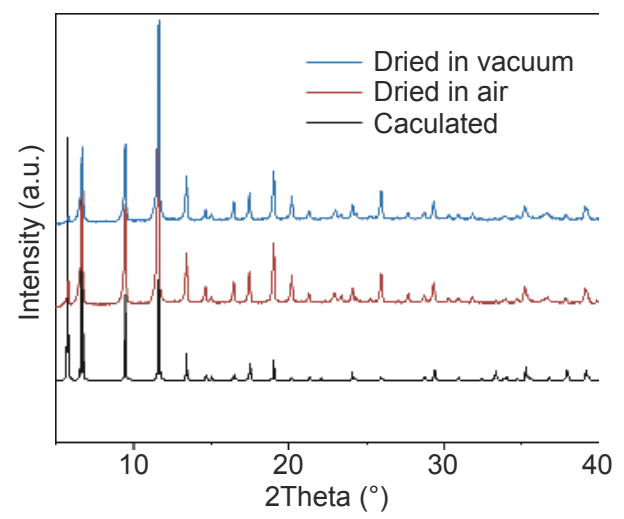

Fig. 4 The X-ray diffractograms of $\mathrm{Cu}$-BTC under different dry conditions.

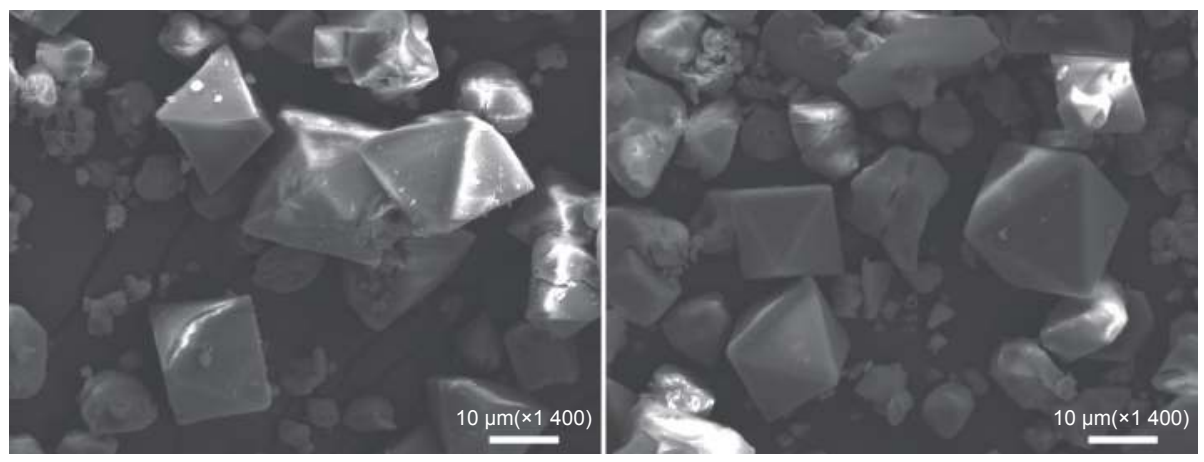

Fig. 5 The faceted octahedral structure of Cu-BTC in the SEM images.
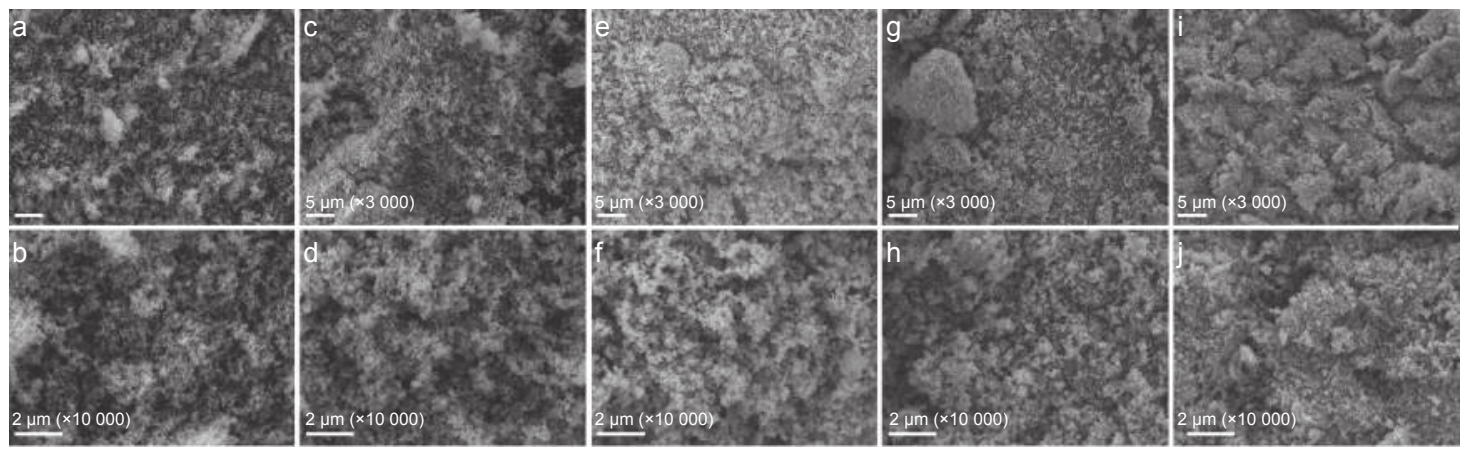

Fig. 6 The SEM images of CZ (a), (b), CZC-0.5 (c), (d), CZC-1 (e), (f), CZC-2 (g), (h), CZC-4 (i), (j) at $5 \mu \mathrm{m}$ (x3,000 magnification) and $2 \mu \mathrm{m}$ (x10,000 magnification) scales. 
bigger than that of $\mathrm{CZ}$ but similar to that of CZC-1, CZC-2 and CZC-4. On the other hand, the nanoparticles on the CZC-1 and CZC-0.5 surfaces were more well-distributed than that of CZC2 and CZC-4. Meanwhile, massive catalyst pieces were commonly found in CZC-4, where nanoparticles on the surface were relatively rare. The differences in the surface structure will influence the MSR reaction performance, which will be discussed later.

The catalysts were further analyzed by the TEM and EDSmapping to verify that copper oxide and zinc oxide were loaded on the Cu-BTC successfully and investigate the nanoparticles on the surface. The TEM images and EDSmapping of CZ, CZC-0.5, CZC-1, CZC-2, CZC-4 are given in Fig. 7 and Fig. 8, respectively. According to Fig. 8(b) and (c), zinc was well dispersed on copper. According to Fig. 7(c), a conclusion can be drawn that the bigger particles of $60 \mathrm{~nm}$ size were copper oxide and the particles of $30 \mathrm{~nm}$ that were connected to copper oxide were zinc oxide. Besides, in Fig. 7(f) and (i), bigger particles of about $100 \mathrm{~nm}$ were observed. According to their EDS-mapping, these particles can be validated as the calcined Cu-BTC. According to the $100 \mathrm{~nm}$ TEM images of the CZCs, smaller copper oxide particles and zinc oxide particles were connected to the bigger particles, which demonstrates the successful support of the calcined $\mathrm{Cu}$ BTC. In Fig. 7(j) and (m), the CZC-2 and CZC-4 suffered severer agglomeration than the CZC-1 and the CZC-0.5. Besides, in Fig. 8(n) and (o), the superfluous Cu-BTC resulted in the uneven distribution of zinc on the copper in CZC-4, where little zinc was observed in several copper particles.

In a word, the XRD patterns of the catalysts indicate the

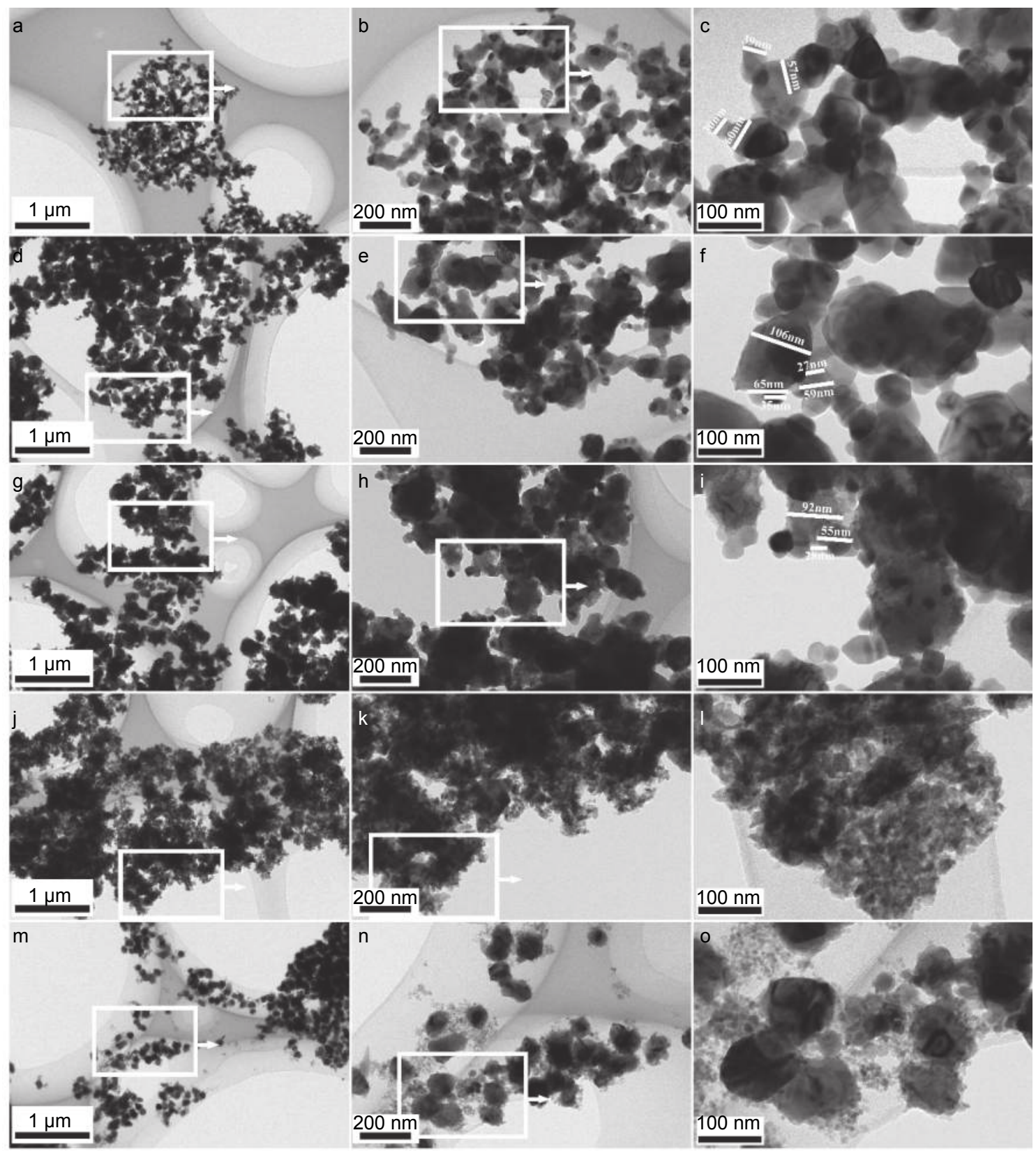

Fig. 7 The TEM images of CZ (a, b, c), CZC-0.5 (d, e, f), CZC-1 (g, h, i), CZC-2 (j, k, l) and CZC-4 (m, n, o) at different magnifications. 


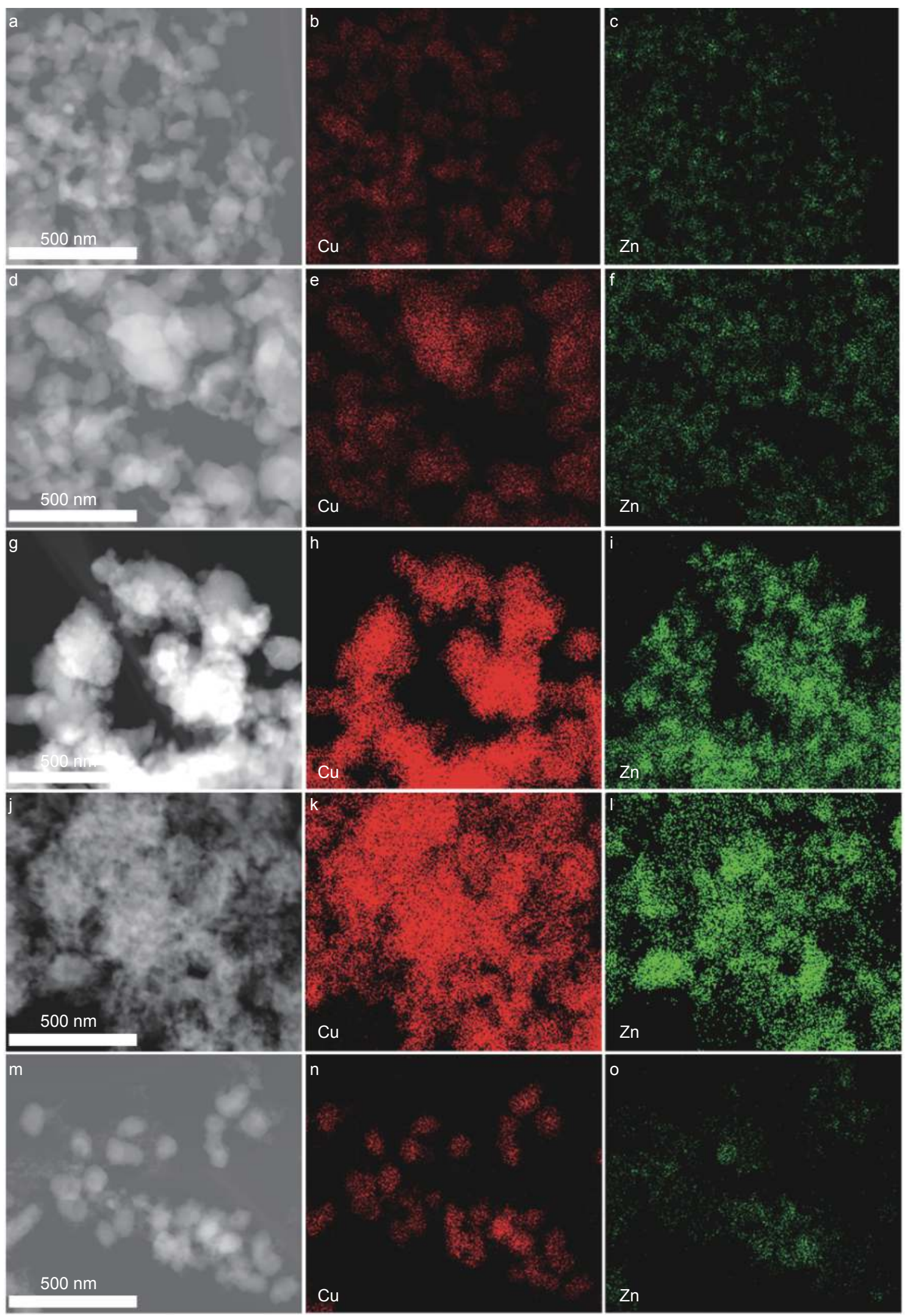

Fig. 8 The element distributions of CZ (a, b, c), CZC-0.5 (d, e, f), CZC-1 (g, h, i), CZC-2 (j, k, l) and CZC-4 (m, n, o) by the EDS-mapping.

successful synthesis of $\mathrm{CuO} / \mathrm{ZnO}$ and $\mathrm{CuO} / \mathrm{ZnO} / \mathrm{Cu}-\mathrm{BTCs}$. The discovery of copper peaks demonstrates the unique property of the $\mathrm{Cu}$-BTC calcined at $500{ }^{\circ} \mathrm{C}$. Moreover, the SEM images, TEM images and EDS-mapping denote that copper oxide and zinc oxide have been successfully loaded on the $\mathrm{Cu}$-BTC and the agglomeration appeared with the superfluous $\mathrm{Cu}-\mathrm{BTC}$.

\subsection{Catalytic activity of $\mathrm{CuO} / \mathrm{ZnO} / \mathrm{Cu}-\mathrm{BTCs}$ and $\mathrm{CuO} / \mathrm{ZnO}$}

The catalysts reacted with methanol and steam at $250{ }^{\circ} \mathrm{C}$ first 
to reduce the $\mathrm{CuO}$ to $\mathrm{Cu}$ referring to Ref. [38]. The methanol steam reforming reaction on the composite catalysts were carried out at $1.2 \mathrm{~atm}, \mathrm{H}_{2} \mathrm{O} / \mathrm{CH}_{3} \mathrm{OH}(\mathrm{S} / \mathrm{C})$ molar ratio of 1.1/1 and weight of catalysts to feed of methanol solution (W/F) ratio of $1.4 \mathrm{~g} \cdot \mathrm{min} / \mathrm{mL}$, and various reaction temperatures were tested in the range of $200-340{ }^{\circ} \mathrm{C}$. Catalyst mixture $(1 \mathrm{~g}$ catalyst mixed with $1 \mathrm{~g}$ quartz sand) was continuously tested at each temperature condition, where quartz sand aimed to increase the aspect ratio of the catalyst bed and prevent the catalyst particle from overheating. Each test took about eight hours to stabilize the syngas ingredient concentration. When the hydrogen concentration of the syngas remained unchanged, the flow rate of the syngas would be recorded. Then the reacting temperature would be raised by $20^{\circ} \mathrm{C}$ and a new test begun. The hydrogen concentration and the carbon monoxide concentration were constantly detected by the gas chromatograph (GC-2014). Eight data around the peak concentration were recorded, and the mean values of the eight data were defined as the exact hydrogen and carbon monoxide concentrations at each temperature.

The values of hydrogen concentration and hydrogen selectivity at different reaction temperatures for the different catalysts are shown in Fig. 9 and the mass fractions of carbon monoxide and hydrogen are shown in Table 1. According to Fig. 9(a) and Table 1, at the low temperature zone from $200{ }^{\circ} \mathrm{C}$ to $240{ }^{\circ} \mathrm{C}$, the $\mathrm{CZ}$ showed better catalytic performance. According to Roselin et al. ${ }^{[39]}$, the catalytic performance of the

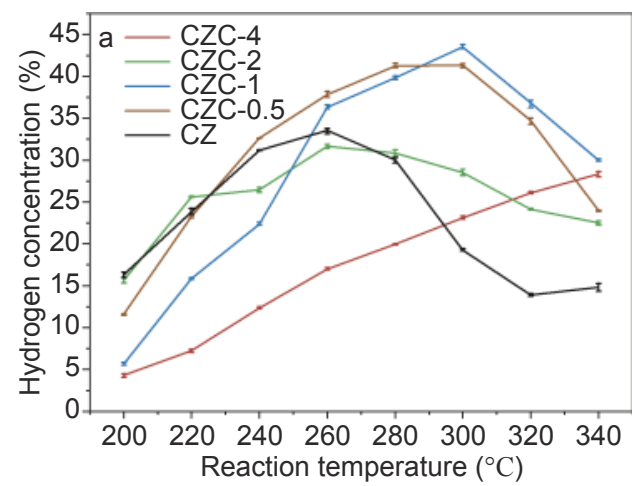

catalysts fluctuated greatly with the change of the weight ratio of copper at relative low temperature, which might have led to the worse catalytic performance of CZCs. When the temperature went higher, the hydrogen concentration of $\mathrm{CZ}$ decreased from $33.52 \%$ at $260{ }^{\circ} \mathrm{C}$ to $30.05 \%$ at $280{ }^{\circ} \mathrm{C}$ and $19.26 \%$ at $300{ }^{\circ} \mathrm{C}$, indicating that $\mathrm{CZ}$ suffered severe catalytic deterioration when the reaction temperature was above $260^{\circ} \mathrm{C}$. Whereas, no obvious catalytic deterioration happened for CZC0.5 and $\mathrm{CZC}-1$ until $300{ }^{\circ} \mathrm{C}$. The hydrogen concentrations of CZC- 0.5 and CZC-1 at $260{ }^{\circ} \mathrm{C}$ were increased by $13 \%$ and $9 \%$, respectively, compared with that of $\mathrm{CZ}$ at $260{ }^{\circ} \mathrm{C}$. While at $300{ }^{\circ} \mathrm{C}$, the hydrogen concentrations of CZC- 0.5 and $\mathrm{CZC}-1$ were increased by $115 \%$ and $126 \%$, respectively, compared with that of $\mathrm{CZ}$. Concerning $\mathrm{CZC}-2$, the performance was close to that of $\mathrm{CZ}$ before $280{ }^{\circ} \mathrm{C}$. Notably, the hydrogen concentration of CZC-2 kept $28.52 \%$ at $300{ }^{\circ} \mathrm{C}$ and $24.12 \%$ at $320{ }^{\circ} \mathrm{C}$, which were much higher than that of $\mathrm{CZ}$. Therefore, the overall hydrogen concentration of CZC-2 was still better than that of CZ. As for CZC-4, despite of the relatively lower hydrogen concentrations at relatively low temperatures, the increase of the hydrogen concentration with the reaction temperature was steady and no catalytic deterioration was found. The catalytic performance of CZC-4 even surpassed CZ and $\mathrm{CZC}-2$ at $320^{\circ} \mathrm{C}$.

In summary, the above results show that the addition of $\mathrm{Cu}$-BTC contributed to the improvement of catalytic activity and anti-deactivation ability at the temperature higher than

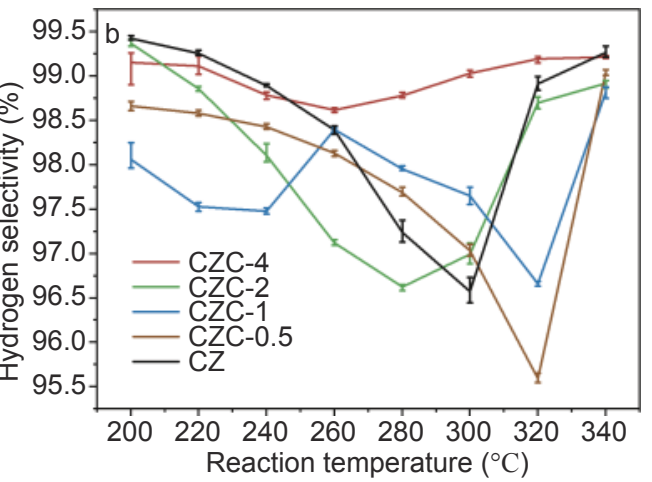

Fig. 9 The values of hydrogen concentration (a) and hydrogen selectivity (b) at different reaction temperatures for the $\mathrm{CuO} / \mathrm{ZnO} / \mathrm{Cu}-\mathrm{BTCs}$ and $\mathrm{CuO} / \mathrm{ZnO}(\mathrm{S} / \mathrm{C}=1.1, \mathrm{~W} / \mathrm{F}=1.4)$.

Table 1. Outlet gas component and mass fraction at different temperatures

\begin{tabular}{cccccccccccc}
\hline & \multicolumn{2}{c}{$\mathrm{CZ}(\%)$} & \multicolumn{2}{c}{$\mathrm{CZC}-0.5(\%)$} & \multicolumn{2}{c}{$\mathrm{CZC}-1(\%)$} & \multicolumn{2}{c}{ CZC-2 (\%) } & \multicolumn{2}{c}{ CZC-4 (\%) } \\
\cline { 2 - 10 } & $\mathrm{H}_{2}$ & $\mathrm{CO}$ & $\mathrm{H}_{2}$ & $\mathrm{CO}$ & $\mathrm{H}_{2}$ & $\mathrm{CO}$ & $\mathrm{H}_{2}$ & & $\mathrm{CO}$ & $\mathrm{H}_{2}$ & $\mathrm{CO}$ \\
\hline 200 & 92.5 & 7.5 & 84.1 & 15.9 & 78.3 & 21.7 & 91.9 & 8.1 & 89.4 & 10.6 \\
220 & 90.5 & 9.5 & 83.2 & 16.8 & 73.8 & 26.2 & 86.1 & 13.9 & 88.8 & 11.2 \\
240 & 86.5 & 13.5 & 81.7 & 18.3 & 73.4 & 26.6 & 78.7 & 21.3 & 85.3 & 14.7 \\
260 & 81.4 & 18.6 & 78.9 & 21.1 & 81.4 & 18.6 & 70.7 & 29.3 & 83.6 & 16.4 \\
280 & 71.5 & 28.5 & 75.1 & 24.9 & 77.3 & 22.7 & 67.2 & 32.8 & 85.3 & 14.7 \\
300 & 66.8 & 33.2 & 70.0 & 30.0 & 74.8 & 25.2 & 69.7 & 30.3 & 88.0 & 12.0 \\
320 & 86.7 & 13.3 & 60.8 & 39.2 & 67.4 & 32.6 & 84.4 & 15.6 & 89.8 & 10.2 \\
340 & 90.6 & 9.4 & 88.0 & 12.0 & 85.7 & 14.3 & 86.7 & 13.3 & 90.0 & 10.0 \\
\hline
\end{tabular}


$260{ }^{\circ} \mathrm{C}$. However, the performance of the $\mathrm{CZCs}$ was influenced by the quality of $\mathrm{Cu}-\mathrm{BTC}$ added and the microstructure of the catalysts. For CZC- 0.5 and $\mathrm{CZC}-1$, due to the well-dispersed nanoparticles on the surface of the catalysts, they possessed the best catalytic activity and delayed its decay temperature to $320^{\circ} \mathrm{C}$. As for CZC-2, the overloaded $\mathrm{Cu}$-BTC resulted in slightly agglomeration as seen in the microstructure characterization, which caused the lower hydrogen concentration at temperatures higher than $260{ }^{\circ} \mathrm{C}$. Concerning CZC-4, the superfluous Cu-BTC caused severe agglomeration according to the SEM images (Fig. 6(h) and (j)) and TEM images (Fig. 7(j) and (m)), where uneven distribution of nanoparticles on the surface was also observed. The unsatisfying microstructure of CZC-4 resulted in the worst catalytic activity at low temperatures while the overloaded $\mathrm{Cu}$ BTC ensured no decline of hydrogen concentration at higher temperatures.

In Fig. 9(b), the hydrogen selectivity of $\mathrm{CZ}$ showed the highest values in the temperature range from $200{ }^{\circ} \mathrm{C}$ to $260{ }^{\circ} \mathrm{C}$. Due to the significant decline of hydrogen concentration at the higher temperatures, the hydrogen selectivity of $\mathrm{CZ}$ decreased from $98.39 \%$ at $260{ }^{\circ} \mathrm{C}$ to $97.24 \%$ at $280{ }^{\circ} \mathrm{C}$ and $96.57 \%$ at $300{ }^{\circ} \mathrm{C}$. For CZC-0.5, CZC-1 and CZC-2, the hydrogen selectivity tended to decrease with the reaction temperature at the temperature range between $200{ }^{\circ} \mathrm{C}$ and $300{ }^{\circ} \mathrm{C}$ from the overall perspective. For $\mathrm{CZ}$ and $\mathrm{CZC}-2$ at $320{ }^{\circ} \mathrm{C}$, the hydrogen selectivity experienced a sudden increase and the same condition could be found for CZC-0.5 and CZC- 1 at $340{ }^{\circ} \mathrm{C}$ as well, whose hydrogen selectivity increased to $99.04 \%$ and $98.82 \%$ respectively.

Combining with the three reactions mentioned in the introduction, we believe that the catalytic performance of the catalysts should be separated into two parts including the ability to generate hydrogen (reaction (2) and reaction (3)) and the ability to generate carbon monoxide (reaction (2)). When the ability for $\mathrm{CZ}$ and $\mathrm{CZC}-2$ to generate hydrogen by reaction (3) which is exothermic declined at the temperatures higher than $260{ }^{\circ} \mathrm{C}$, the ability to generate carbon monoxide by reaction (2) didn't decline until $300{ }^{\circ} \mathrm{C}$ for $\mathrm{CZ}$ and $280{ }^{\circ} \mathrm{C}$ for $\mathrm{CZC}-2$, which resulted in the continuously decrease of hydrogen selectivity. When the temperature was higher than $300{ }^{\circ} \mathrm{C}$ for $\mathrm{CZ}$ and $\mathrm{CZC}-2$, the reaction (2) was receded, which led to the decrease of the $\mathrm{CO}$ generated and hence the sudden increase of the hydrogen selectivity. The hydrogen generation rate shown in Fig. 10 which decreased at the temperature higher than $300{ }^{\circ} \mathrm{C}$ proves the recession of the reaction (2). For CZC- 0.5 and CZC-1, the sudden increase of the hydrogen selectivity at $320{ }^{\circ} \mathrm{C}$ could be explained by the same way as the CZC-2, while the turning points of CZC- 0.5 and CZC-1 were delayed to $320{ }^{\circ} \mathrm{C}$ because of appropriate $\mathrm{Cu}$ BTC added. However, the hydrogen selectivity of CZC-1 was relatively low at temperature below $260{ }^{\circ} \mathrm{C}$, which could be attributed to that a small part of CZC-1 unreduced consumed a

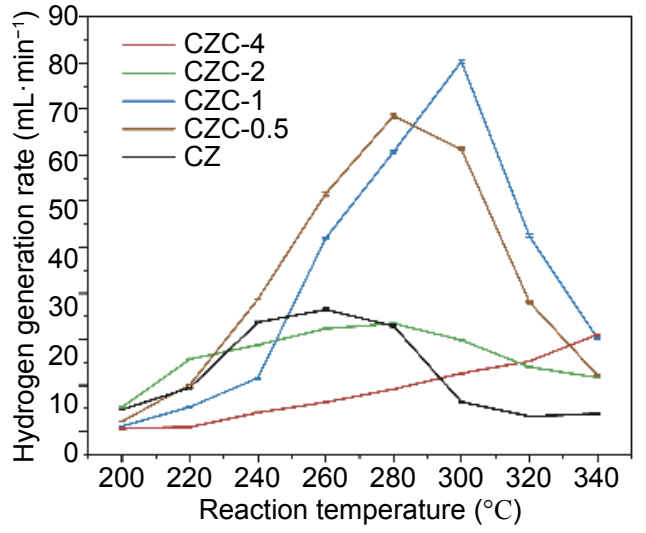

Fig. 10 The values of hydrogen generation rate at different reaction temperatures for the $\mathrm{CuO} / \mathrm{ZnO} / \mathrm{Cu}-\mathrm{BTCs}$ and $\mathrm{CuO} / \mathrm{ZnO}(\mathrm{S} / \mathrm{C}=1.1$, $\mathrm{W} / \mathrm{F}=1.4)$.

part of generated hydrogen. When the temperature was increased to $260{ }^{\circ} \mathrm{C}$, the reduction was fully completed, leading to the regular hydrogen selectivity. Meanwhile, the overall hydrogen selectivity of CZC-4 was the best, and even the lowest hydrogen selectivity was higher than $98.5 \%$. According to the higher hydrogen selectivity of CZC-4, where the majority of the copper came from $\mathrm{Cu}-\mathrm{BTC}$, it was suspected that the copper calcined from $\mathrm{Cu}$-BTC might possess a unique structure to depress the yield of carbon monoxide. Overall, the hydrogen selectivity of CZCs was still kept at a relatively high level (higher than 95\%).

The hydrogen generation rates of the catalysts at different reaction temperatures are shown in Fig. 10. In the temperature range from $200{ }^{\circ} \mathrm{C}$ to $240{ }^{\circ} \mathrm{C}$, little difference existed for $\mathrm{CZ}$, CZC-0.5 and CZC-1. However, the hydrogen generation rate of CZC- 0.5 was increased by $95 \%$ at $260{ }^{\circ} \mathrm{C}, 199 \%$ at $280{ }^{\circ} \mathrm{C}$, $857 \%$ at $300{ }^{\circ} \mathrm{C}$ and $759 \%$ at $320{ }^{\circ} \mathrm{C}$ respectively, compared with the hydrogen generation rate of $\mathrm{CZ}$, while the hydrogen generation rate of CZC-1 was increased by $59 \%$ at $260{ }^{\circ} \mathrm{C}$, $165 \%$ at $280{ }^{\circ} \mathrm{C}, 1155 \%$ at $300{ }^{\circ} \mathrm{C}$ and $1196 \%$ at $320{ }^{\circ} \mathrm{C}$, respectively. With respect to $\mathrm{CZC}-2$, the hydrogen generation rate was similar to that of $\mathrm{CZ}$ until $280{ }^{\circ} \mathrm{C}$. Whereas, the hydrogen generation rate of CZC-2 was increased by $119 \%$ at $300{ }^{\circ} \mathrm{C}$ and $328 \%$ at $320{ }^{\circ} \mathrm{C}$ compared with that of CZ. CZC-4 showed the lowest rates at the temperature range from $200{ }^{\circ} \mathrm{C}$ to $280{ }^{\circ} \mathrm{C}$, but surpassed $\mathrm{CZ}$ at $300{ }^{\circ} \mathrm{C}$ and $320{ }^{\circ} \mathrm{C}$. Likewise, the drop of hydrogen generation rate started at $280^{\circ} \mathrm{C}$ for $\mathrm{CZ}$, $300{ }^{\circ} \mathrm{C}$ for CZC- $0.5,320{ }^{\circ} \mathrm{C}$ for CZC- 1 and $300{ }^{\circ} \mathrm{C}$ for CZC-2, while no decline happened for CZC-4. Generally, the trend of CZCs in the hydrogen generation rate was consistent with that in the hydrogen concentration shown in Fig. 9(a). Whereas, taking $300{ }^{\circ} \mathrm{C}$ as example, compared with only about $100 \%$ growth in the hydrogen concentration, the hydrogen generation rates of CZC- 0.5 and CZC- 1 were increased by about ten times. This could be caused by the fact that the contact area between catalysts and reactants was increased benefiting from the welldistributed nanoparticles on the surface of CZC- 0.5 and CZC- 1 
(as shown in Fig. 6(d) and (f)), and further confirmed the positive effect of $\mathrm{Cu}-\mathrm{BTC}$ on the catalytic activity.

The values of carbon monoxide concentration and carbon monoxide selectivity at different reaction temperatures of the different catalysts are presented in Fig. 11. Combining with Fig. 9, Fig. 11(a) and (b) further verifies that the temperature where the ability to generate hydrogen decayed was lower than the temperature where the ability to generate carbon monoxide

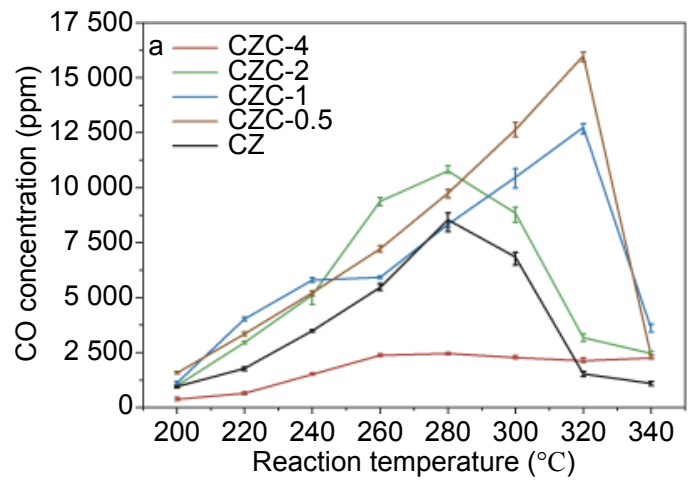

decayed. Besides, CZ, CZC-0.5, CZC-1 and CZC-2 showed little distinction in the ability of carbon monoxide depression according to Fig. 11(a). Whereas, the $\mathrm{CO}$ selectivity and concentration of CZC-4 were kept at a low level during the whole tests. This indicates the copper calcined from $\mathrm{Cu}$-BTC as the majority catalytic matter might have positive effects on the carbon monoxide depression, which was consistent with the discussion in Fig. 9(b).

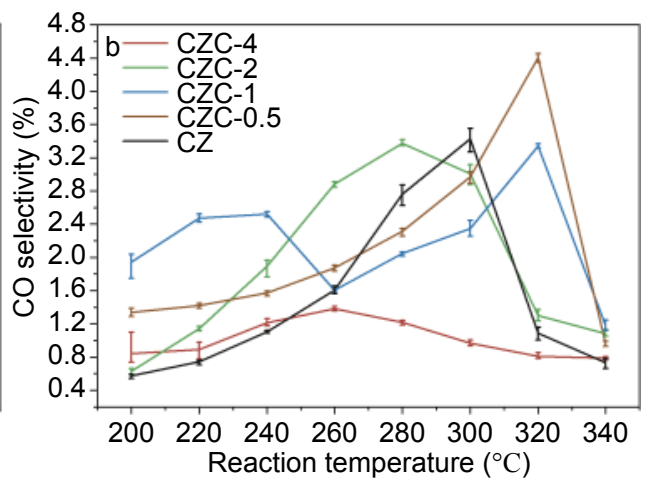

Fig. 11 The values of $\mathrm{CO}$ concentration (a) and $\mathrm{CO}$ selectivity (b) at different reaction temperatures for the $\mathrm{CuO} / \mathrm{ZnO} / \mathrm{Cu}-\mathrm{BTCs}$ and $\mathrm{CuO} / \mathrm{ZnO}$ $(\mathrm{S} / \mathrm{C}=1.1, \mathrm{~W} / \mathrm{F}=1.4)$.

\subsection{Deactivation of $\mathrm{CuO} / \mathrm{ZnO} / \mathrm{Cu}-\mathrm{BTCs}$ and $\mathrm{CuO} / \mathrm{ZnO}$}

The SEM images of the catalysts after long-time reaction were illustrated in Fig. 12. As is illustrated, it is obvious that the particle size of the CZCs expanded with the increase of the $\mathrm{Cu}$ BTC addition, where the particle of CZC-4 was too big to find a separated unit. The bigger small stings could be observed in CZC-0.5, CZC-1 and CZC-4 while the stings in CZC-2 were long enough to be called as branches. Combining with the catalytic activity in section 3.2, the small stings could be viewed as the effective structure that delayed the decay of the catalytic performance to the higher temperature. Whereas, the branches in CZC-2 was so giant (micrometer scale) compared with the small stings (nanometer scale) that the reaction dynamic might be disturbed, which made the catalytic performance of CZC-2 decay ahead at $280^{\circ} \mathrm{C}$.
Taking CZC-1 as the example, the mechanism of the catalytic deterioration was analyzed by Fig. 13. Fig. 13(a) and (b) show the SEM images of CZC-1 before and after the whole reaction tests. It could be seen that the size of the particles on the surface after the reaction tests (around $500 \mathrm{~nm}$ ) was much bigger than that before the reaction tests (around $150 \mathrm{~nm}$ ), which indicates the agglomeration was formed during the sintering of copper particles. The agglomeration of the particles caused the deactivation of the catalysts. On the other hand, based on Xu et al. ${ }^{[5]}$ and Li et al., ${ }^{[40]}$ zinc oxide can inhibit the sintering of copper during the reaction. Considering the agglomeration and the inhibitation ? of zinc oxide mentioned above, the catalyst deactivating process can be illustrated as seen in Fig. 13(c). After long-time reaction, several copper particles that were closed to each other sintered into one bigger

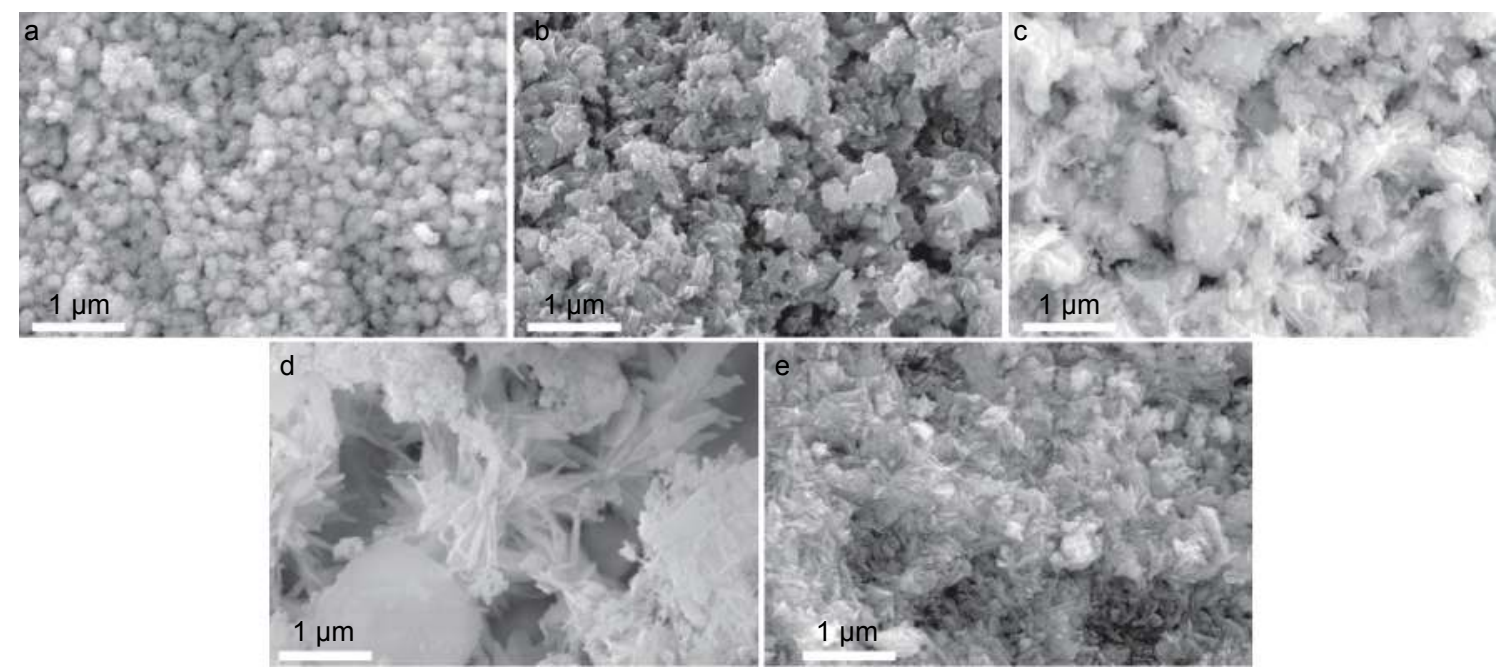

Fig. 12 The SEM images of CZ (a), CZC-0.5 (b), CZC-1 (c), CZC-2 (d) and CZC-4 (e) after long-time reaction. 


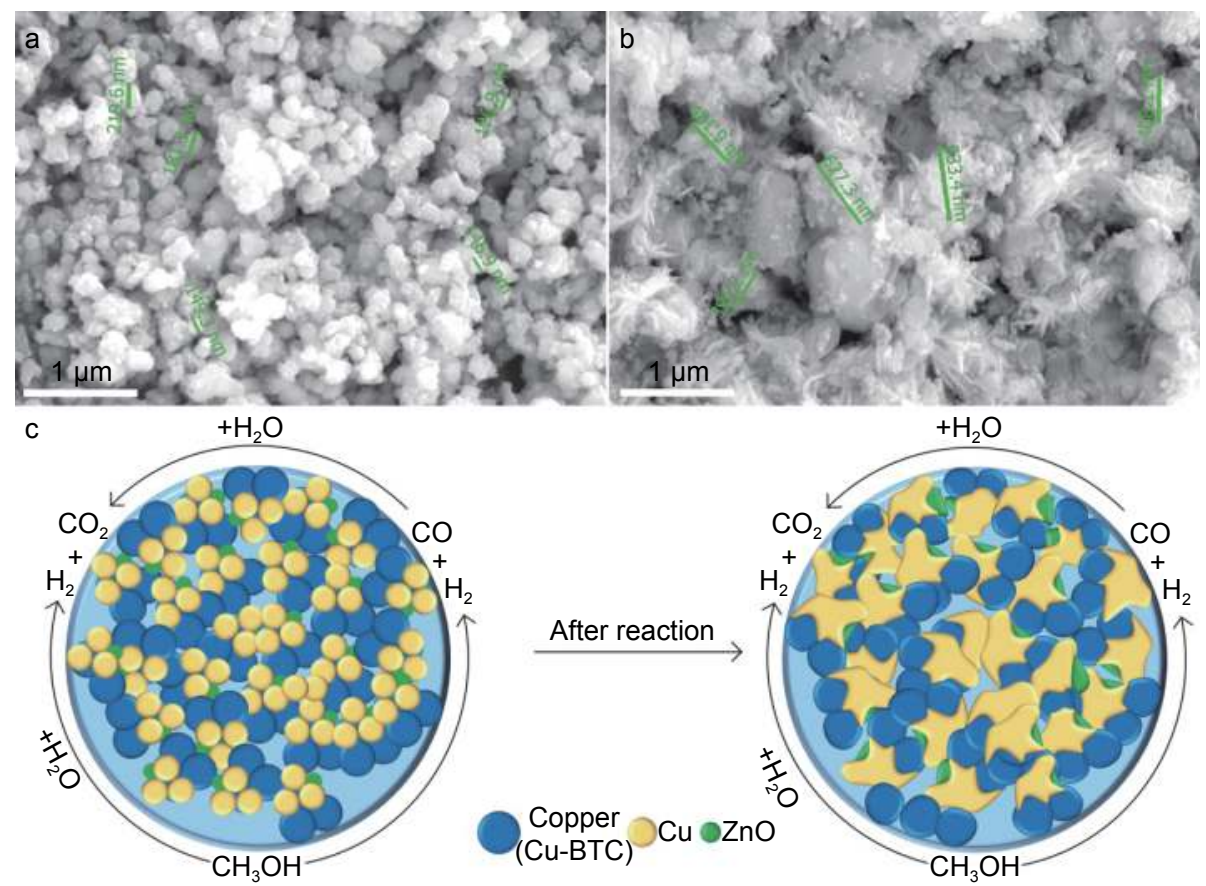

Fig. 13 (a) The SEM image of CZC-1 before the MSR reaction, (b) the SEM image of CZC-1 after the MSR reaction, and (c) the illustration of copper sintering process.

copper particle, while the copper particles separated by $\mathrm{ZnO}$ particles did not sinter together into giant particles.

\subsection{Stability of $\mathrm{CuO} / \mathrm{ZnO} / \mathrm{Cu}-\mathrm{BTCs}$ and $\mathrm{CuO} / \mathrm{ZnO}$}

To study the stability performance of the catalysts, a 24-hour stability test was applied at $260{ }^{\circ} \mathrm{C}$. To begin with, the rank of the hydrogen generation rate was consistent with that in Fig. 10. The average values of eight data around the peak rate in the beginning and eight data at the end were recorded in Table 1, where the mean decay rates of the catalysts during the 24 hours were demonstrated as well. According to Fig. 14 and Table 2, the stability performance of $\mathrm{CZ}$ was the worst, whose decline rate was nearly as twice as that of CZCs. In this case, the addition of $\mathrm{Cu}$-BTC was of great beneficial to the stability performance. Integrating with the catalytic activity mentioned in section 3.2, CZC-1 possessed the best catalytic performance from the overall perspective, whose stability performance,

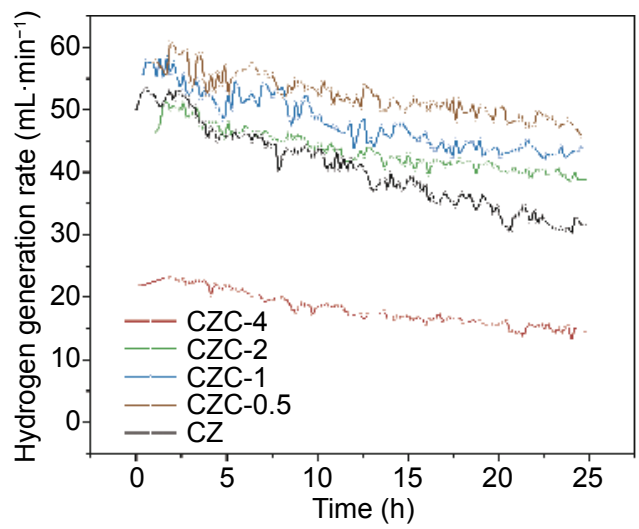

Fig. 14 The values of the hydrogen generation rate during the 24-hour stability test at $260{ }^{\circ} \mathrm{C}$ for the catalysts.
Table 2. Catalytic performance decline of the catalysts

\begin{tabular}{ccccc}
\hline & $\begin{array}{c}\text { Starting rate } \\
\left(\mathrm{mL} \cdot \mathrm{min}^{-1}\right)\end{array}$ & $\begin{array}{c}\text { End rate } \\
\left(\mathrm{mL} \cdot \mathrm{min}^{-1}\right)\end{array}$ & $\begin{array}{c}\text { Difference } \\
\left(\mathrm{mL} \cdot \mathrm{min}^{-1}\right)\end{array}$ & $\begin{array}{c}\text { Decline rate } \\
\left(\mathrm{mL} \cdot \mathrm{min}^{-1} / \mathrm{h}\right)\end{array}$ \\
\hline $\mathrm{CZ}$ & 52.00 & 31.34 & 20.65 & 0.86 \\
$\mathrm{CZC}-0.5$ & 56.35 & 48.43 & 7.91 & 0.33 \\
$\mathrm{CZC}-1$ & 55.24 & 43.89 & 11.35 & 0.47 \\
$\mathrm{CZC}-2$ & 47.17 & 40.02 & 7.15 & 0.30 \\
$\mathrm{CZC}-4$ & 22.76 & 15.25 & 7.51 & 0.31 \\
\hline
\end{tabular}

though, was unsatisfying. CZC-2 standing out in the stability test showed inferior catalytic activity. Whereas, the catalytic activity of CZC- 0.5 was close to that of CZC-1, and CZC- 0.5 also demonstrated fine stability performance. In conclusion, from the aspect of both catalytic activity and stability performance, CZC-0.5 was the best. However, it is also predicted that there would be an optimal loading mass between $0.5 \mathrm{~g}$ and $1 \mathrm{~g}$, which endows the catalyst with both high catalytic activity and superior stability performance.

\section{Conclusion}

In this paper, $\mathrm{CuO} / \mathrm{ZnO}$ was loaded on different masses of $\mathrm{Cu}$ BTC to improve the catalytic activity, anti-deactivation ability and stability performance of the catalysts for methanol steam reforming reaction. The $\mathrm{CuO} / \mathrm{ZnO} / \mathrm{Cu}-\mathrm{BTCs}$ and the $\mathrm{Cu}-\mathrm{BTC}$ were characterized by XRD, SEM, TEM and EDS-mapping, which confirmed the successful synthesis of the materials. Meanwhile, an MSR system with a conventional fixed bed tubular-quartz reactor was developed to study the catalytic activity, anti-deactivation ability and stability performance of $\mathrm{CuO} / \mathrm{ZnO} / \mathrm{Cu}$-BTCs at the temperature from $200{ }^{\circ} \mathrm{C}$ to $340{ }^{\circ} \mathrm{C}$. The results showed that proper addition of $\mathrm{Cu}-\mathrm{BTC}$ (e.g., $0.5 \mathrm{~g}$ 
and $1 \mathrm{~g}$ ) endowed the catalysts with splendid microstructures, where nanoparticles were uniformly distributed on the surface. Benefiting from the excellent microstructures, the hydrogen concentration and hydrogen generation rate of $\mathrm{CZC}-0.5$ and CZC-1 were increased by about $100 \%$ and $1000 \%$, respectively, compared with the regular $\mathrm{CuO} / \mathrm{ZnO}$ catalyst at $300{ }^{\circ} \mathrm{C}$. Moreover, the unique stings formed on the surface of the reacted particles delayed the deterioration temperature of CZC- 0.5 and CZC- 1 to $320^{\circ} \mathrm{C}$ compared with the deactivation of $\mathrm{CuO} / \mathrm{ZnO}$ at $280{ }^{\circ} \mathrm{C}$. For $\mathrm{CZC}-2$, the overloaded $\mathrm{Cu}-\mathrm{BTC}$ resulted in the uneven distribution of nanoparticles on the catalysts surface and the micrometer-scale branches formed on the surface during the reaction, which made CZC-2 to deactivate in advance at $280{ }^{\circ} \mathrm{C}$. However, CZC-2 still showed higher hydrogen concentration and hydrogen generation rate at the temperatures higher than $260{ }^{\circ} \mathrm{C}$ compared with the $\mathrm{CuO} / \mathrm{ZnO}$. As for CZC-4, the superfluous $\mathrm{Cu}-\mathrm{BTC}$ caused severe agglomeration, which led to lower hydrogen concentration and lower hydrogen generation rate at the temperatures below $300{ }^{\circ} \mathrm{C}$. Whereas, CZC-4 showed no deterioration during the whole test, which suggests that the copper calcined from the $\mathrm{Cu}-\mathrm{BTC}$ could be of a unique structure with excellent anti-deactivation ability. Meanwhile, the stability test confirmed that $\mathrm{Cu}$-BTC could improve the stability performance of the catalysts. In summary, $\mathrm{CuO} / \mathrm{ZnO} / \mathrm{Cu}$-BTCs showed better catalytic activity, antideactivation ability and stability performance at the temperatures higher than $260{ }^{\circ} \mathrm{C}$ due to the dual-functional ability of $\mathrm{Cu}-\mathrm{BTC}$, and thus show great potential as excellent catalysts for hydrogen generation through methanol steam reforming reaction.

\section{Acknowledgments}

The authors would like to thank the support of the National Natural Science Foundation of China (Project No. 51876061, $51821004)$.

\section{Supporting information}

Not applicable

\section{Conflict of interest}

There are no conflicts to declare.

\section{References}

[1] A. J. De Jong, F. Trausel, C. Finck, L. Van Vliet and R. Cuypers, Energy Procedia, 2014, 48, 309-319.

[2] P. Haseli, M. Jafarian and G. J. Nathan, Sol. Energy, 2017, 153, $1-10$.

[3] M. Benitez-Guerrero, J. M. Valverde, P. E. Sanchez-Jimenez, A. Perejon and L. A. Perez-Maqueda, Sol. Energy, 2017, 153, 188-199.

[4] A. Singh, S. Tescari, G. Lantin, C. Agrafiotis, M. Roeb and C. Sattler, Sol. Energy, 2017, 144, 453-465.
[5] X. Xu, K. Shuai and B. Xu, Catalysts, 2017, 7, 183.

[6] M. Madej-Lachowska, M. Kulawska and J. Słoczyński, Chem. Process Eng., 2017, 38, 147-162.

[7] C. H. Liao and R. F. Horng, Int. J. Hydrogen Energ., 2016, 41, 4957-4968.

[8] W. Fuqiang, J. Lin, C. Ziming, L. Huaxu and T. Jianyu, Int. J. Hydrogen Energ., 2019, 44, 15795-15810.

[9] Y. Ando, Int. J. Hydrogen Energ., 2019, 44, 18724-18731.

[10] A. Iulianelli, P. Ribeirinha, A. Mendes and A. Basile, Renew. Sust. Energ. Rev., 2014, 29, 355-368.

[11] F. Zhang, Y. Shi, L. Yang and X. Du, Sci.Bull., 2016, 61, 401-405.

[12] X. Gu, R. A. Taylor, Q. Li, J. A. Scott and G. Rosengarten, Sol. Energy, 2015, 113, 189-198.

[13] J. Wang, J. Wu, Z. Xu and M. Li, Energ. Convers. Manage., 2017, 150, 81-89.

[14] D. Real, I. Dumanyan and N. Hotz, Int. J. Hydrogen Energ., 2016, 41, 11914-11924.

[15] Y. J. Chiu, H. C. Chiu, R. H. Hsieh, J. H. Jang and G. J. Syu, Energy Procedia, 2017, 105, 1622-1627.

[16] F. Vidal Vázquez, P. Simell, J. Pennanen and J. Lehtonen, Int. J. Hydrogen Energ., 2016, 41, 924-935.

[17] N. Manjula, R. Balaji, K. Ramya, K. S. Dhathathreyan, N. Rajalakshmi and A. Ramachandraiah, Int. J. Hydrogen Energ., 2018, 43, 562-568.

[18] J. Tian, Y. Ke, G. Kong, M. Tan, Y. Wang, J. Lin, W. Zhou and S. Wan, Renew. Energ., 2017, 113, 30-42.

[19] I. Coronado, M. Stekrova, L. García Moreno, M. Reinikainen, P. Simell, R. Karinen and J. Lehtonen, Biomass Bioenerg., 2017, 106, 29-37.

[20] C. Mateos-Pedrero, H. Silva, D. A. Pacheco Tanaka, S. Liguori, A. Iulianelli, A. Basile and A. Mendes, Appl. Catal. B-Environ., 2015, 174, 67-76.

[21] Y. C. Pu, S. R. Li, S. Yan, X. Huang, D. Wang, Y. Y. Ye and Y. Q. Liu, Fuel, 2019, 241, 607-615.

[22] I. Kasatkin, P. Kurr, B. Kniep, A. Trunschke and R. Schlögl, Angew. Chem. Int. Edit., 2007, 46, 7324-7327.

[23] R.Thattarathody and M. Sheintuch, Appl. Catal. A-Gen., 2017, 540, 47-56.

[24] L. Zhang, L. W. Pan, C. J. Ni, T. J. Sun, S. D. Wang, Y. K. Hu, A. J. Wang and S. S. Zhao, Journal of Fuel Chemistry and Technology, 2013, 41, 883-888.

[25] C. C. Chang, C. T. Chang, S. J. Chiang, B. J. Liaw and Y. Z. Chen, Int. J. Hydrogen Energ., 2010, 35, 7675-7683.

[26] M. Pan, Q. Wu, L. Jiang and D. Zeng, Appl. Energ., 2015, 154, 416-427.

[27] W. Zhou, Y. Ke, Q. Wang, S. Wan, J. Lin, J. Zhang and K. S. Hui, Fuel, 2017, 191, 46-53.

[28] S. S. Y. Chui, S. M. F. Lo, J. P. H. Charmant, A. G. Orpen and I. D. Williams, Science, 1999, 283, 1148-1150.

[29] B. F. Hoskins and R. Robson, J. Am. Chem. Soc., 1990, 112, $1546-1554$.

[30] B. F. Hoskins and R. Robson, J. Am. Chem. Soc., 1989, 111, 5962-5964.

[31] J. Gascon, A. Corma, F. Kapteijn and F. X. Llabrés I Xamena, ACS Catal., 2013, 4, 361-378.

[32] J. Rocha, L. D. Carlos, F. A. A. Paz and D. Ananias, Chem Soc Rev, 2011, 40, 926-940.

[33] Allendorf MD, Bauer CA, Bhakta RK, et al, Chem. Soc. Rev., 2009, 38, 1330-1352.

[34] Q. Yang, J. P. Zhao, B. W. Hu, X. F. Zhang and X. H. Bu, Inorg. 
Chem., 2010, 49, 3746-3751.

[35] A. N. Ökte, D. Karamanis, E. Chalkia and D. Tuncel, Mater. Chem. Phys., 2017, 187, 5-10.

[36] L. H. Wee, N. Janssens, S. R. Bajpe, C. E. A. Kirschhock and J. A. Martens, Catal. Today, 2011, 171, 275-280.

[37] Y. Zhao, C. Zhong and C. J. Liu, Catal. Commun., 2013, 38, 74-76.

[38] E. Xiao, Liu H, Qian S, et al, Industrial Catalysis, 2016, 24,
$35-41$.

[39] L. Selva Roselin and H. W. Chiu, J. Saudi Chem. Soc., 2018, 22, 692-704

[40] D. Li, X. Li and J. Gong, Chem. Rev., 2016, 116, 11529-11653.

Publisher's Note: Engineered Science Publisher remains neutral with regard to jurisdictional claims in published maps and institutional affiliations. 